\title{
Ocean Plastic Debris Forecast and Control Model
}

\author{
Dongping Wei \\ Math and Physics Department \\ Shenzhen Polytechnic, \\ Shenzhen, 518055; \\ wdp@szpt.edu.cn
}

\begin{abstract}
The North Pacific Ocean Garbage patch increasing model is proposed in this paper to forecast the ocean plastic area in next decade. According to the model, the area of the garbage patch in the north pacific central gyre will grow to double sizes of Texas in next ten years. The models based on four controlling strategies are proposed to predict the effects.
\end{abstract}

Keywords-Ocean Plastic Debris, control Model,Marine ecosystem, The North Pacific Garbage Patch

\section{INTRODUCTION}

In summer times, the north pacific section where between the west coast of the United States and Hawaii, and the northeast area of Hawaiian Islands, will be under the control of continuous high pressure, and form a "quiet area". Shown in Fig.1,the north Pacific Ocean Gyre is formed by different ocean clockwise currents such as California current and north pacific drift, where the marine debris will be involved into the Gyre what is so called "quiet area" [1]. Recently, marine scientists survey that most marine debris, which has wider and wider distribution, higher and higher density, and harm to the ocean ecosystem more and more seriously.

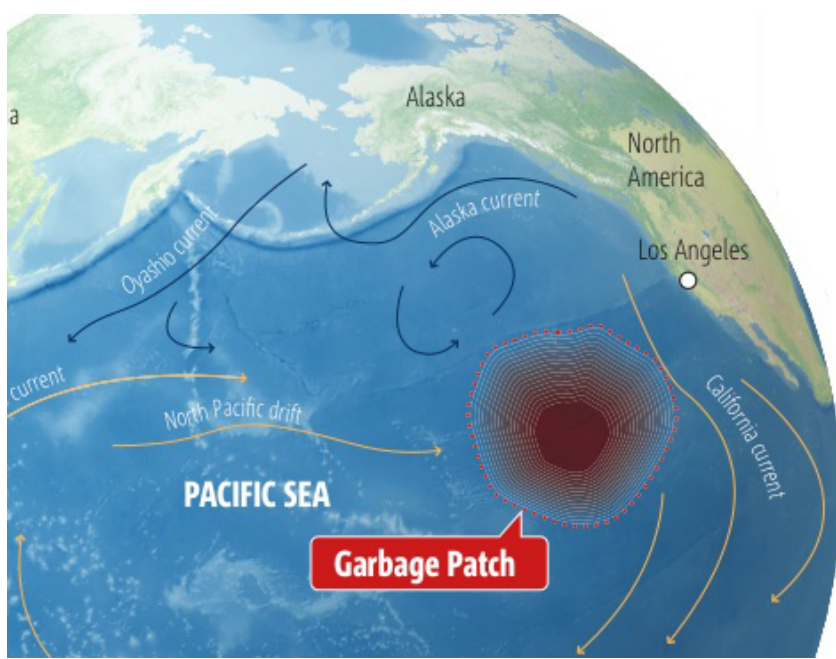

Fig. 1. The north Pacific Ocean Gyre

The debris is existing in long-term and accumulating continually in the ocean environment such as endanger the navigation safety of ships, water pollutions, causing the marine organisms and mammals deaths [2]. The North Pacific Ocean Garbage patch almost in Texas size is getting larger and larger, which will be mankind's and ocean's nightmare [3]. Therefore, it is crucial to research the sources of garbage on the north pacific gyre and the increasing rules of the abundance of the plastic debris, and then put forward some reasonable and economical controlling measures in order to protecting marine ecosystem.

\section{AsSUMPTIONS AND NotATIONS}

UNEP statistics shows that plastic occupies $90 \%$ of the entire ocean floating garbage. The unable-degraded plastic garbage in longtime will seriously harm marine ecosystem. Researchers consider mainly about the sources of ocean plastic gyre and the increasing rules of the abundance of the plastic debris. Researchers classify the plastic garbage under three types: marco-debris( $>20 \mathrm{~mm})$, meso-debris $(2 \sim 20 \mathrm{~mm})$, microdebris $(<2 \mathrm{~mm})$. For analyzing easily, we mainly study the observable floating plastic debris such as macro-debris and meso-desbris. As we known, plastic debris in the marine environment derive from two main sources: rubbish dumped from ships at sea and land-based sources such as runoff from rivers, waste water systems, wind-blown litter and recreational litter left on beaches (Coe\&Rogers 1997). In addition, researchers consider the floating plastic debris on ocean only, because a part of plastic debris should be sinking to the seabed during their ways to the ocean (Fig. 2).

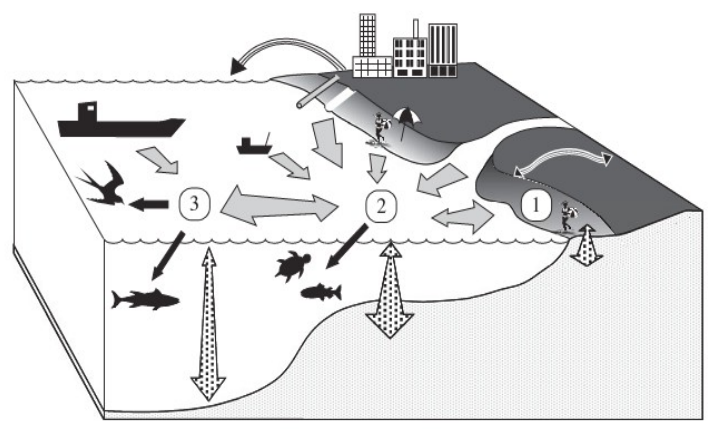

Fig. 2. Plastic debris sources

Fig.2 shows the main sources and movement pathways for plastics in the marine environment, with sinks occurring (1) on beaches, (2) in coastal waters and their sediments and (3) in the open ocean. Curved arrows depict wind-blown litter, grey arrows water-borne litter, stippled arrows vertical movement through the water column (including burial in sediments) and black arrows ingestion by marine organisms. 
And some plastics degrade to fragments in a long period, so a little amount of floating ocean garbage decreases consequently. Due to the different degrading time of the different plastic, researchers assume the degraded proportion of the existed plastic debris is relatively fixed for simplification.

The key notations and definitions of variables in the next section are introduced as follows:

$y_{\text {new-added-t } t}$ :The new added ocean garbage annually

$\alpha_{\text {ships }}$ :Sinking ratio of the plastic debris from ships

$\alpha_{\text {rivers }}$ : Sinking ratio of the plastic debris drift from rivers

$\alpha_{\text {water }}$ :Sinking ratio of the plastic debris from waste water systems litters

$\alpha_{\text {wind }}$ : Sinking ratio of the plastic debris by wind-blown

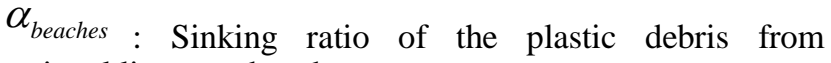
recreational litters on beaches

$X_{\text {ships }}$ : the amount of garbage from ships

$X_{\text {rivers }}$ : the amount of garbage from rivers

$X_{\text {water }}$ : the amount of garbage from waste water systems

$X_{\text {wind }}$ : the amount of garbage from wind-blown litters

$X_{\text {beaches }}$ : the amount of garbage from recreational litters on beaches

$\beta_{d}$ : the average degraded rate of different plastic

$y_{t}$ : the total amount of garbage in year $\mathrm{t}$

$\bar{y}_{t-1}$ :the total amount of garbage in the year (t-1)

\section{The OCEAn Garbage Patch INCREAsing ModeL}

It is necessary to propose mathematical model to predict the amount of ocean plastic debris in next ten years according to the garbage sources, laws of increasing. It is popular and economical to use plastic products, so the plastic debris is dumping to ocean continually.

The two main sources of garbage include ships and landbased sources. $y_{\text {land }-t}$ is the amount of ocean garbage new added by the land-based sources. $y_{\text {ships- } t}$ is the amount of ocean garbage new added by the ship-based sources. Hence, the amount of ocean garbage new added annually $y_{\text {new-added }-t}$ can be calculated by the following Eq.(1).

$$
y_{\text {new-added }-t}=y_{\text {land }-t}+y_{\text {ships }-t}
$$

$\bar{y}_{t-1}$ is denoted as the amount of the existing ocean garbage in year t. A part of the floating plastic debris is degraded in certain time. The average of degradation rate is $\beta_{d}$ in every year. The total amount of ocean garbage in year $\mathrm{t}$ can be calculated by the following Eq.(2).

$$
y_{t}=y_{\text {new-added }-t}+\left(1-\beta_{d}\right) \bar{y}_{t-1}
$$

Garbage from Land-based sources mainly includes rivers, waste water systems, wind-blown litter and recreational litters on beaches. $X_{\text {rivers }}$ is denoted as the new garbage drift from rivers. $X_{\text {ships }}$ is denoted as the new garbage from ships. $X_{\text {wind }}$ is the new garbage from wind-blown litter. $X_{\text {beaches }}$ is denoted as the new garbage from recreational litters on beaches . $\alpha_{\text {ships }}$ is the sinking proportion of garbage from ships. $\alpha_{\text {rivers }}$ is the sinking proportion of garbage from rivers. $\alpha_{\text {water }}$ is the sinking proportion of garbage from waste water systems. $\alpha_{\text {wind }}$ is the sinking proportion of garbage from wind-blown litters. $\alpha_{\text {beaches }}$ is the sinking proportion of garbage from recreational litters. Then the North Pacific Ocean Garbage patch increasing model can be calculated as following Eq.(3)

$$
\begin{aligned}
y_{\text {new-added }} & =\left(1-\alpha_{\text {ships }}\right) X_{\text {ships }}+\left(1-\alpha_{\text {rivers }}\right) X_{\text {rivers }}+\left(1-\alpha_{\text {wind }}\right) X_{\text {wind }} \\
& +\left(1-\alpha_{\text {water }}\right) X_{\text {water }}+\left(1-\alpha_{\text {beaches }}\right) X_{\text {beaches }}
\end{aligned}
$$

Assumed the average sinking proportion from sources is $20 \%$. The garbage patch of the North Pacific Ocean gyre is produced by the following main countries: USA, Japan, Australia, China. The increasing rate of garbage per year in Japan is about $5.4 \%$. And the garbage flows to the North Pacific Ocean Gyre finally. By the Eq.(3), we can predict the area of the garbage patch of the North Pacific Ocean gyre will expand to double size in next decades shown as Fig.3.
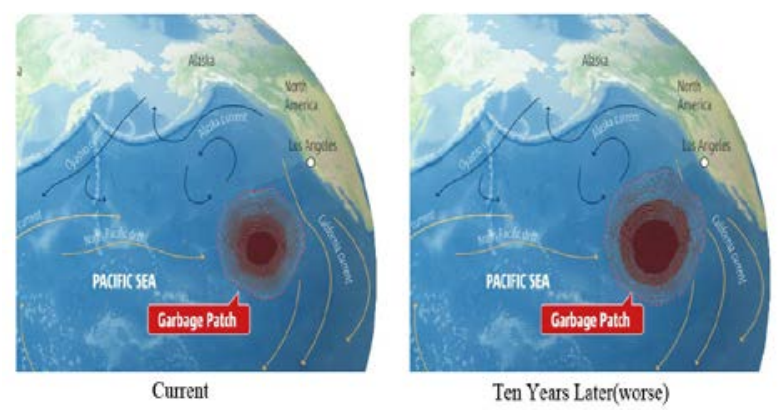

Fig. 3. The garbage patch in North Pacific Center gyre in next decade 


\section{The NorTh PACIFIC Garbage PATCH CONTROLling MODEL}

From the Ocean Garbage patch increasing model, it can be seen that the amount of north pacific garbage patch is increasing continuously. It is sure that there is more and more serious threat to marine ecosystem and the safety of human. Therefore, controlling the increasing amount of plastic effectively is becoming much more important issue. According to authority statistics, the proportion of plastic garbage from land-based source is nearly $80 \%$, so it should limit the abundance of garbage from land-based source in order to control ocean plastic garbage more effectively.

On the other hand, we should publicize the harm of ocean garbage extensively and decrease the use of non-degradable plastic products. Under these controlling ways, we build models for the following four controlling strategies, and predict the effect, and then take Japan as an example.

(1) Regular litter collection on beaches (RLCS). From Regular litter collection on beaches, the amount of plastic decrease rate is $\gamma_{\text {beaches }}$. Without any other controlling strategies, we can get Garbage collection controlling model (GCC-Model) for new added ocean garbage per year as below:

$$
\begin{gathered}
y_{\text {new-added }}=\left(1-\alpha_{\text {ships }}\right) X_{\text {ships }}+\left(1-\alpha_{\text {rivers }}\right) X_{\text {rivers }}+\left(1-\alpha_{\text {wind }}\right) X_{\text {wind }} \\
+\left(1-\alpha_{\text {water }}\right) X_{\text {water }}+\left(1-\alpha_{\text {beaches }}-\gamma_{\text {beaches }}\right) X_{\text {beaches }}
\end{gathered}
$$

According to the data, assumed the $\gamma_{\text {beaches }}$ of Japan in 1990 is $1 \%$, and with the increasing funds of Collecting Projects and the raising public awareness on environmental issues, the $\gamma_{\text {beaches }}$ increase $1 \%$ per year. From the GCCModel, the changes before and after practice RLCS is shown in Fig.4. After practicing RLCS, the annual amount of litter is decreasing year after year in Japan.

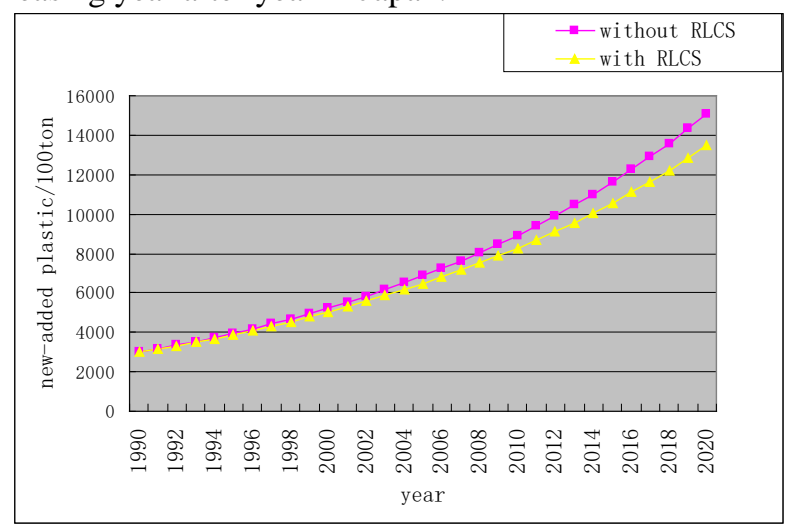

Fig. 4. The Changes Before and After Practicing RLCS

(2) Screaming system strategy (SSS-Model) and enhancing the garbage filters in the urban catchment \& rivers. Denoted $\gamma_{\text {water }}, \gamma_{\text {rivers }}$ for the decreasing rate after SSS, we can get the annual new added ocean garbage:

$$
\begin{aligned}
y_{\text {new-added }} & =\left(1-\alpha_{\text {ships }}\right) X_{\text {ships }}+\left(1-\alpha_{\text {rivers }}-\gamma_{\text {rivers }}\right) X_{\text {rivers }}+\left(1-\alpha_{\text {wind }}\right) X_{\text {wind }} \\
& +\left(1-\alpha_{\text {water }}-\gamma_{\text {water }}\right) X_{\text {water }}+\left(1-\alpha_{\text {beaches }}\right) X_{\text {beaches }}
\end{aligned}
$$

According to the data, $\gamma_{\text {water }}$ and $\gamma_{\text {rivers }}$ are $20 \%$, so we can get the effeteness curves of Screaming System Strategy by the SSS-Model. Shown in Fig.5, the new added ocean garbage increasing rate has decreased greatly after practicing SSS. So the effect of this Screaming system strategy is quiet obviously.

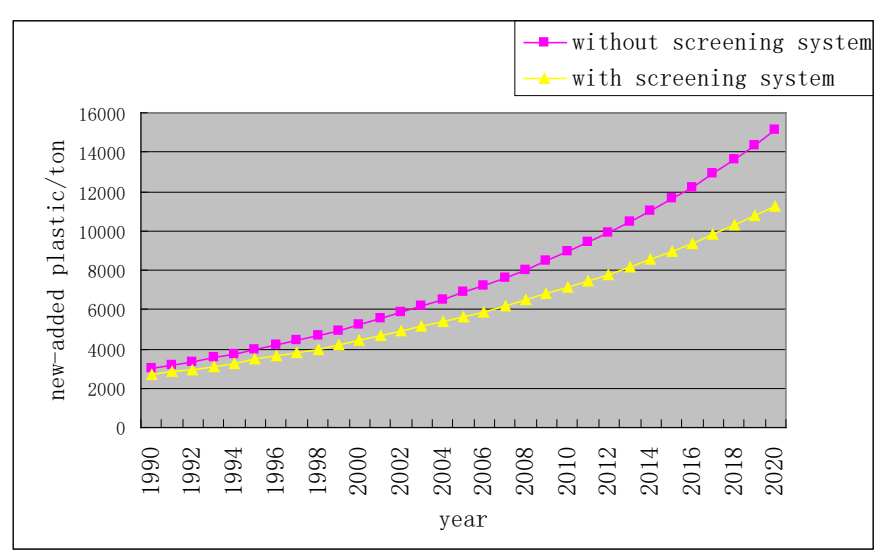

Fig. 5. The effeteness of Screaming System Strategy

(3) Reducing the Release of the Plastic and banning polystyrene takeout contained Polystyrene (RBP-Model)

Cut down the consumption of plastic products (such as pay for plastic bags), prohibit the usage of some non-gradable plastic product like polystyrene. Assumed the usage amount of plastic has decreased 5\% after 1990, and the annual plastic decreasing-usage amount rate is $1 \%$, then it can know the new added ocean garbage in the year $\mathrm{t}$ :

$$
\begin{aligned}
y_{\text {new-added-t }}= & {\left[\begin{array}{l}
\left(1-\alpha_{\text {ships }}\right) X_{\text {ships }}+\left(1-\alpha_{\text {rivers }}\right) X_{\text {rivers }}+\left(1-\alpha_{\text {wind }}\right) X_{\text {wind }} \\
+\left(1-\alpha_{\text {water }}\right) X_{\text {water }}+\left(1-\alpha_{\text {beaches }}\right) X_{\text {beaches }}
\end{array}\right] } \\
& \times[1-5 \%-(t-1990)]
\end{aligned}
$$

According to the data and RBP-Model, Fig. 6 shows that the effect of decreasing the plastic usage amount is the most obviously. It can lead to the dumping of the plastic garbage decrease as much as possible.

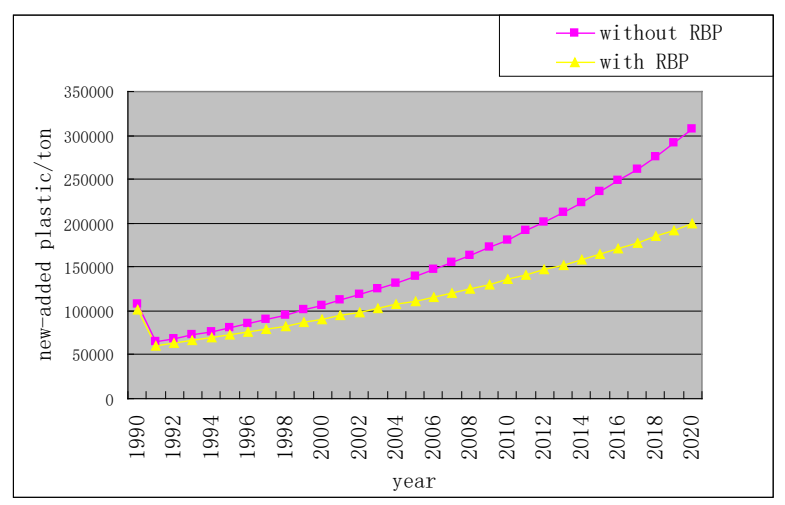

Fig. 6. The changes Before And After Practicing RBP.

(4) Integrated the above 3 strategies to control plastic garbage derived from land-based sources. So we can get an 
annual new added ocean garbage integrated controlling model(IC-model):

$$
\begin{aligned}
y_{\text {new_added }} & =\left(1-\alpha_{\text {ships }}-\gamma_{\text {ships }}\right) X_{\text {ships }}+\left(1-\alpha_{\text {rivers }}-\gamma_{\text {rivers }}\right) X_{\text {rivers }} \\
& +\left(1-\alpha_{\text {wind }}-\gamma_{\text {wind }}\right) X_{\text {wind }}+\left(1-\alpha_{\text {water }} \gamma_{\text {water }}\right) X_{\text {water }} \\
& +\left(1-\alpha_{\text {beaches }}-\gamma_{\text {beaches }}\right) X_{\text {beaches }}
\end{aligned}
$$

According to the data and IC-Model, we can get the changes before and after integrated controlling. After integrated controlling strategies including RLCS and SSS and $\mathrm{RBP}$, we can find that the annual new added ocean plastic garbage dumping to the ocean has decreased near 60\%.Moreover, Fig.7 shows the effect is getting better and better.

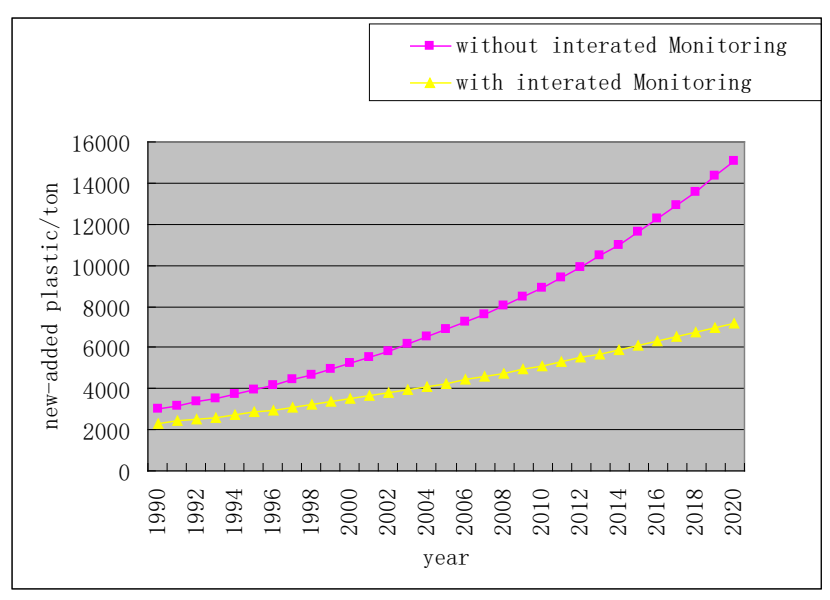

Fig. 7. The New Added Plastic in North Pacific Before and After Integrated controlling.

Practicing the integrated controlling strategies along the Asia-Pacific countries, the increment of North Pacific Garbage Patch could be slow down greatly. We can predict by IC-model the situation of North Pacific Garbage Patch in next decade is shown in Fig.8 (left). If cleaning-up the current garbage gradually through international cooperation, the patch is trending to reduce in next ten years shown as Fig. 8 (right).

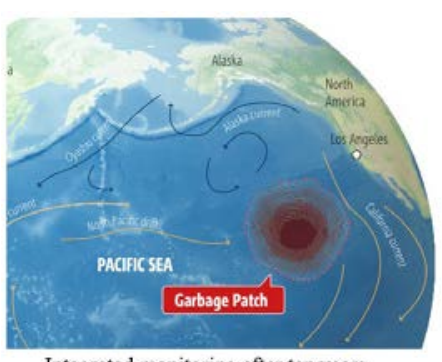

Integrated monitoring after ten years

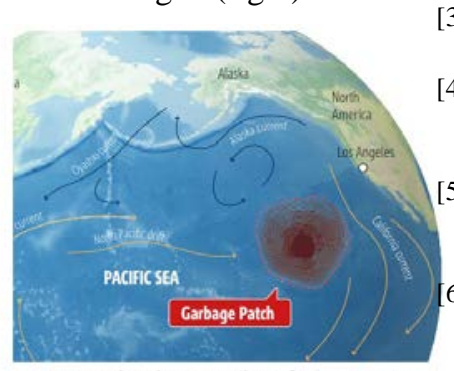

International cooperation after ten years

\section{CONCLUSIONS AND SugGESTIONS}

Nowadays, the performance of plastic improves constantly and plastic products become diversified along with the rapid development of the plastic industry. So the plastic production and usage amount and applied range are enlarging rapidly. In this case, if we do not take any measures to control the plastic pollution issue, the consequence should be tragedy. In addition to speed up the research and industrialization of biodegradable plastic, we should consider the following controlling strategies:

(1)Firstly, legislate to limit the plastic improper usage and ban the optionally dumping plastic debris to sea, and monitor the law implementation strictly.

(2) Widely spreading environment protection issues by newspapers, TV shows, pamphlets, seminars and other forms.

(3) Providing education courses on environment pollutions issues, environment protection laws for ocean beneficiaries such as fishermen and sailors.

(4)Organizing much more environmental protection activities such as cleaning beaches regularly and voluntarily, these activities can raise public awareness on environmental issues.

(5) Setting much more litter collections devices in the harbors and communities, and then reuse the plastic.

\section{ACKNOWLEDGMENT}

This work is supported by Social Science Foundation of Guangdong (Grant No. GD14XGL03).And the authors would like to thank the editor and an anonymous referee for their helpful comments on the manuscript.

\section{REFERENCES}

[1] Freebody M. THE GREAT PACIFIC GARBAGE PATCH[J]. The Environmental Magazine, 2011, 28(3):8.

[2] Moore C J, Moore S L, Leecaster M K, et al. A Comparison of Plastic and Plankton in the North Pacific Central Gyre[J]. Marine Pollution Bulletin, 2001, 42(12):1297-1300.

[3] Pyrek C. Plastic Paradise: The Great Pacific Garbage Patch (review)[J]. Contemporary Pacific, 2016, 28.

[4] Harse G A. Plastic, the great pacific garbage patch, and international misfires at a cure[J]. Ucla Journal of Environmental Law \& Policy, 2011, 29(2):331-363.

[5] Dautel S L. Transoceanic Trash: International and United States Strategies For the Great Pacific Garbage Patch[J]. Golden Gate U.envtl.l.j, 2009, 3(3):181-208.

6] Sigler M. The effects of plastic pollution on aquatic wildlife: current situations and future solutions.[J]. Water Air \& Soil Pollution, 2014, 225(11):1-9.

Fig. 8. The North Pacific Garbage Patch ten years later 